\title{
O ESTADO NATURAL E A VERDADEIRA LIBERDADE DO SÚDITO EM TH. HOBBES
}

José N. Heck*

SÍNTESE - O artigo retoma a interpretação de Macpherson do estado natural e a confronta com a concepção hobbesiana da verdadeira liberdade dos súditos. O trabalho expōe os desafios teónicos do fisicalismo vital na obra de Hobbes e assume e posição de que 0 teórico político inglês não prova que os homens evitam pela luta e ou pela fuga a morte violenta movidos unicamente por uma necessidade natural. PALAVRAS-CHAVE - Hobbes. Estado de natureza. A verdadeira liberdade do súdito. Macpherson.
ABSTRACT - The article takes Macpherson's interpretation of the state of nature and confronts it with Hobbes' conception of the true liberty of the subject. The paper shows the theoretical challenges of vital physicalism in Hobbes' work and assumes that the English political theoretician doesn't get to prove that men avoid violent death by fighting or fleeing moved only by a natural necessity. KEY-WORDS - Hobbes. State of nature. The true liberty of a subject. Macpherson.

\section{Introdução}

A despeito de seu elevado grau de abstração, a remissão hobbesiana do político ao natural é vista por Rousseau como ilusória. Reportando-se aos jusnaturalistas, o genebrino escreve no segundo Discurso: "Enfim, todos, falando incessantemente de necessidade, avidez, opressão, desejo e orgulho, transferiram ao estado de natureza idéias que nasceram na sociedade; falavam do homem selvagem e descreviam 0 homem civil". ${ }^{1}$ Hegel considera a fantasia do estado de natureza, oscilando entre o que é por necessidade e o que constitui mera coisa do pensamento (Gedankending), a mais dura das contradições. ${ }^{2}$ Para ambos os críticos do status naturae hobbesiano,

* Professor da UFG (Universidade Federal de Goiás), da UCG (Universidade Católica de Goiás) e Pesquisador do CNPq.

1 ROUSSEAU, Jean-J. Discours sur l'origine et les fondements de l'inégalité parmi les hommes. In: Oeuvres complètes III. Paris: Gallimard, 1964, p. 132. "Enfin tous, parlant sans cesse de besoin, d'avidité, d'oppression, de desirs, et d'orgueil, ont transporté à l'état de Nature, des idées qu'ils avoient prises dans la société; ils parloient de l'Homme Sauvage et ils peignoient l'Homme Civil" (versão portuguesa, p. 49).

2 HEGEL, Georg. Über die wissenschaftlichen Behandlungsarten des Naturrechts, seine Stelle in der praktischen Philosophie, und sein Verhältnis zu den positiven Rechtswissenschaften. Jenaer Kritische Schriften (II). Hrsg. von H. Brockard und H. Buchner. Hamburg: Meiner, 1983, p. 99-100. 


\section{$O$ individualismo possessivo}

Tomando por base a obra-prima do teórico político inglês, Macpherson tipifica como possessive market society a referência que subjaz à ficção hobbesiana do estado natural. Tal tipificação se opõe à admissão de que 0 fato de o estado de natureza não ser, para Hobbes, uma hipótese histórica, prescreveria como necessária uma hipótese lógica que prescindisse de todas as propriedades adquiridas pelos homens no decorrer da história. De acordo com Macpherson, pelo contrário, o estado natural hobbesiano resulta da inferência de um tipo de paixão que molda o homem civilizado na ausência de um poder comum, ou seja, refere-se àquele comportamento que homens civilizados assumiriam quando ninguém mais exigisse a observância das leis e daquilo que está devidamente acordado entre eles. ${ }^{3}$ Para chegar ao estado de natureza, "Hobbes desconsidera a lei, mas não as condutas e os desejos humanos socialmente adquiridos". ${ }^{4}$

A reconstrução macphersoniana da hipótese do status naturalis ocorre em dois planos. No primeiro, as paixões das quais Hobbes infere a constituição natural dos homens são consideradas induzidas por uma civilização cuja lógica é, num segundo plano, rastreada nas consequiências que as paixões civilizatórias adquirem na situação de guerra generalizada do estado natural. Tal método vem em auxilio de quem tem dificuldades para aceitar que a natureza tenha dissociado os homens e talvez deseja, como Hobbes admite, "não confiando nesta inferência, feita a partir das paixões, que a mesma seja confirmada pela experiência". ${ }^{5}$ A reconstrução também faz jus à posição hobbesiana segundo a qual a hipótese do estado de natureza não é invalidada pela existência do status civilis. Para Macpherson, a condição natural dos homens é ubíqua e não está isolada dos homens no tempo e no espaço. Abstraído da autoridade, o estado hobbesiano de natureza é onipresente. "[...] é fácil conceber", escreve Hobbes, "qual seria o gênero de vida quando não havia poder comum a recear, através do gênero de vida em que os homens que anteriormente viveram sob um governo pacífico costumam deixar-se cair, numa guerra civil". ${ }^{6}$

3 MACPHERSON, Crawford B. The political theory of possessive individualism - Hobbes to Locke. London/Oxford/New York: Oxford University Press, 1962, p. 22. "His 'inference made from the passions' could be made from the passions of existing men, passions shaped by civilized living. His inferences were so made. His state of nature is a statement of the behaviour to which men as they now are, men who live in civilized societies and have the desires of civilized men, would be led if all law and contract enforcement (...) were removed" (versão portuguesa, p. 33).

4 Ibidem. "To get the state of nature, Hobbes has set aside law, but not the socially acquired behaviour and desires of men".

Leviathan I, 13, p. 89. "It may seem strange to some man [...] that Nature should thus dissociate, and render men apt to invade, and destrpy one another; and he may therefore, not trusting to this Inference, made from the Passions, desire perhaps to have the same confirmed by Experience" (versão portuguesa, p. 80). Ibidem. "[...] it may be perceived what manner of life there would be, where there were no common Power to feare; by the manner of life, which men that have formerly lived under a peacefull government, use to degenerate into, in a civill Warre". 
Na medida em que o princípio construtivista hobbesiano se torna indistinto do processo de abstração da incipiente sociedade capitalista, Macpherson é forçado a conceber a ficção do estado natural como simples negação da sociedade civilizada, a saber: sem indústria, nem cultivo da terra, nem navegação, nem arquitetura, tampouco artes, letras e ciências. Como tal negação só poderia adquirir positividade no âmbito de uma sistematização dialética, a reconstrução macphersoniana é sustentada pela concomitante conversão da ficção do estado natural num determinado estádio do desenvolvimento humano. $\mathrm{O}$ que em Hobbes mantém-se alheio à periodização histórica torna-se característica marcante de uma sociedade que faz do mercado para o trabalho o critério do capitalismo e já induz Marx a citar o Leviatã, ${ }^{7}$ traduzindo por força de trabalho (Arbeitskraft) $)^{8}$ o valor-preço de um homem no mercado, o que corresponde em Hobbes ao "uso de seu poder". Como uma generalização empírica não vem ao caso para Macpherson, o estado natural perfaz o reverso abstrato do nascente capitalismo moderno. ${ }^{10}$

Com concepções diametralmente opostas a tal formatação histórica, Horkheimer vê no state of nature hobbesiano um fixismo antropológico alheio e hostil a qualquer senso historiográfico.$^{11} \mathrm{~A}$ relevância da interpretação macphersoniana está na descoberta de um descompasso na constância monofásica atribuída por Horkheimer ao estado de natureza do teórico político inglês. Enquanto o frankfurtiano engessa a hipótese do estado natural hobbesiano, Macpherson registra uma clivagem entre o plano fisiológico do homem, como corpo em movimento, e o plano social do homem como agente que atua voltado ao semelhante. Como os axiomas mecanicistas de Hobbes não cobrem o universo social, limitados que estão ao plano fisiológico, Macpherson suspeita que a hipótese do estado natural opera, em Hobbes, com pressupostos sociais específicos, não explicitamente solidificados em princípios, mas nem por isso inativos e inexpressos na doutrina hobbesiana da condição natural da humanidade. A questão delimita-se ao ponto crucial de estabelecer em que lugar de sua trajetória demonstrativa, procedendo do movimento fisiológico em direção à dinâmica social, o teórico político inglês introduz as indispensáveis premissas sociais em seu argumento.

O intérprete canadense localiza o ponto de inserção na definição hobbesiana de poder. Tão-somente 0 acréscimo de premissas sociais aos postulados fisiológi-

7 MARX, Karl. Das Kapital, Kritik der politischen Ökonomie. Bd. I. Berlin: Dietz Verlag, 1972, p. 184, nota 42 MEW, Bd. 23 (versão portuguesa, p. 190).

8 Ibidem. "Diese eigentümliche Ware, die Arbeitskraft, ist nun näher zu betrachten. Gleich allen andren Waren besitzt sie einen Wert".

9 Leviathan I, 10, p. 63. "The Value, or Worth of a man, is as of all other things, his Price; that is to say, so much as would be given for the use os his Power" (versão portuguesa, p. 58).

10

MACPHERSON. Op. cit., p. 59. "The possessive market society, then, does meet Hobbes's requirements. It is a society in which men who want more may, and do, continually seek to transfer to themselves some of the power of others, in such a way as to compel everyone to compete for more power, and all this by peaceable and legal methods which do not destroy the society by open force" (versão portuguesa, p. 68).

1 HORKHEIMER, Max. Anfänge der bürgerlichen Geschichtsphilosophie. Frankfurt/Main: Suhrkamp, 1971 , p. 35. 
cos possibilita, segundo Macpherson, interpretar o poder como ter sempre mais poder sobre outros homens. As supostas premissas são incrustadas no modelo da sociedade de mercado possessivo do século XVII. ${ }^{12}$ Os resultados dessa fixação tipológica trazem à superfície as relações de poder como relações de mercado (a market in power). Como marca individual, o poder tem a fisionomia privada do proprietário burguês e, como grandeza societária, o mesmo poder configura o sistema mercadológico da permuta universal dos bens capitalistas. ${ }^{13}$

Em vez de caracterizar a prevalência hobbesiana do indivíduo como individualismo-de-poder, o enquadramento do fenômeno do poder no circuito do mercado leva Macpherson a caracterizá-lo como individualismo-de-posse. Limitada pela definição do respectivo objeto, a posse de bens móveis ou imóveis implica, em relação ao poder individual, um reducionismo metódico. Por ser apenas um dos meios disponiveis ao indivíduo para usufruir poder, o individualismo possessivo macphersoniano disseca o poder do homem à moda capitalista, ou seja, reserva-lhe eficácia sob os auspícios do capital.

Mesmo que a premissa histórica de Macpherson incida corretamente no capitalismo inglês nascente, o fator econômico é, antes e depois do século XVII, apenas um dentre os vários fatores que articulam e efetivam a consolidação do power market humano. $\mathrm{O}$ interesse do indivíduo em ter poder e mais poder não se atém às regras-de-fé do mercado, mas acolhe qualquer possibilidade interativa para acumular poder, seja ela de caráter cultural, epistêmico, artístico, religioso, político ou armamentista. Por mais desenvolvida que a formação societária da possessive market society tenha estado na época de Hobbes, a incidência da premissa sócio-histórica atinge um vazio teórico da ciência civil hobbesiana. Para o filósofo do individualismo, o que há, por um lado, é o universo de indivíduos em interação e, por outro, o universo estatal. Entre esses pólos não se encontra nenhuma sociedade. ${ }^{14} \mathrm{O}$ primeiro é por natureza e o segundo existe por artifício.

De acordo com a versão hobbesiana do estado natural, o poder pertence à natureza, razão por que também a majestade do Estado é passageira, como tudo que viceja sob o sol. Ao marcar sua contraposição à filosofia política clássica, Hobbes distingue o comportamento de seres humanos do convívio gregário das abelhas e formigas, vivendo socialmente umas com as outras "(e por isso são contadas por Aristóteles entre as criaturas políticas), sem outra direção a não ser seus juízos e apetites particulares, nem linguagem através da qual possam indicar umas às outras o que consideram adequado para o benefício comum". ${ }^{15}$ Comparados com os seres

12 MACPHERSON. Op. cit., p. 61. "There is plenty of evidence that England approximated closely to a possessive market society in the seventeenth century" (versão portuguesa, p. 72).

13 WEISS, Ulrich. Das philosophische System von Thomas Hobbes. Stuttgart-Bad Cannstatt: Frommann-Holzboog, 1992, p. 122.

14 Ibidem, p. 124.

15 Leviathan II, 17, p. 119. "(which are therefore by Aristotle numbred amongst Politicall creatures;) and yet have no other direction, than their particular judgements and appetites; nor speech, whereby one of them can signifie to another, what he thinks expedient for the common benefit" (versão portuguesa, p. 108). 
políticos da tradição, os humanos parecem entes que destoam da ordem natural, isto é, [...] "estão constantemente envolvidos numa competição pela honra e pela dignidade, o que não ocorre no caso dessas criaturas" ${ }^{16}$ Longe de recorrer à tese da degeneração do gênero humano, o teórico político inglês ratifica a naturalidade dos homens e flagra na raiz da eminência do poder o obrar da natureza, que dispensa uma formação societária específica para ser efetiva, "de modo que", conclui Hobbes, "na natureza do homem encontramos três causas principais de discórdia. Primeiro, a competição, segundo a desconfiança e, terceiro, a glória". ${ }^{17}$ Em termos aristotélicos, a "inclinação geral de todos os homens, um perpétuo e irrequieto desejo de poder e mais poder", ${ }^{18}$ não toma, em Hobbes, o caráter de um actus, como atuação plenificadora e posterior à potência, mas constitui a categoria que marca, enquanto potencialidade, o que está cada vez além do presente e em relação à qual toda obra humana se afigura relativa. No âmbito da discussão sobre o necessitarismo, Hobbes responde ao "Catching of the Leviathan" do bispo Bramhall, dizendo que potencialidade equivale à potentia, "o que em inglês é poder" ${ }^{19} \mathrm{O}$ teórico político inglês faz da eminência filosófica do poder - e não da propriedade - a logomarca política da Modernidade.

Ao privilegiar paixões civilizatónias, Macpherson se poupa ao exame do que Hegel visualiza no jusnaturalismo como "a mais dura contradição (der härteste Widerspruch)" ${ }^{20}$ e o que Hobbes chama em sua obra-prima de "a verdadeira liberdade de um súdito" (the true liberty of a subject). ${ }^{21}$ Tal liberdade não resulta do silêncio das leis, mas do fato de que o estado natural continua relevante no estado civil na medida em que é "evidente", para Hobbes, "que todo súdito tem liberdade em todas as coisas cujo direito não pode ser transferido por um pacto". ${ }^{22}$ Para Macpherson, o homem natural é o homem civilizado, apenas com a restrição legal removida. ${ }^{23}$ Ao tomar por civilizadas as paixões que, segundo Hobbes, são naturais, o intérprete perde o contato com o direito natural em acepção hobbesiana. A hipótese macphersoniana, de acordo com a qual há na obra de Hobbes um hiato argumentativo a ser fechado com premissas não adequadamente formuladas pelo teórico político inglês, vinga-se no momento em que se trata de sustentar a consistência teórica do discurso passional do capitalismo emergente, configurado pela sociedade de mercado possessivo.

16 Ibidem. "[...] men are continually in competition for Honour and Dignity, which these creatures are not",

17 Ibidem I, 13, p. 88. "So that in nature of man, we find three principall causes of quarrell. First, Competition; Secondly, Diffidence; Thirdly, Glory" (versão portuguesa, p. 79).

Ibidem I, 11, p. 70. "[...] a generall inclination of all mankind, a perpetuall and restlesse desire of Power after power [...]" (versão portuguesa, p. 64).

19 EW IV, p. 299. "[...] what potentiality is: for I understand it to be the same with potentia, which is in English power".

${ }^{20}$ HEGEL. Über die wissenschaftlichen Behandlungsarten des Naturrechts, seine Stelle in der praktischen Philosophie, und sein Verhältnis zu den positiven Rechtswissenschaften. Jenaer Kritische Schriften (II). Hrsg. von H. Brockard und H. Buchner. Hamburg: Meiner, 1983, p. 100.

22 Leviathan II, 21, p. 150 (versão portuguesa, p. 136).

22 Ibidem II, 21, p. 151. "It is manifest, that every Subject has Liberty in all those things, the right whereof cannot by Covenant be transferred" (versão portuguesa, p. 137).

23 MACPHERSON. Op. cit. p. 29. "Natural man is civilized man with only the restraint of law removed" (versão portuguesa, p. 40). 
Paixões civilizadas são teoricamente consistentes e estão eticamente justificadas pelos argumentos civilizatórios que as enformam discursivamente, de acordo com as peculiaridades da civilização à qual pertencem. No mais tardar na questão da verdadeira liberdade dos súditos, a interpretação macphersoniana despede-se do teórico político inglês.

\section{O individualismo jusnaturalista}

Já The elements expõe que ninguém tem o direito de resistir à espada da justiça, "desde que a não-resistência seja possivel". ${ }^{24}$ Como Hobbes não indica quais são as ações que tem em mente, a afirmação permanece formal e equivale ao ultra posse nemo obligatur do direito romano. Ao retomar o princípio no De cive, o teórico político inglês lhe dedica todo um parágrafo, cuja frase inicial explicita o agir cujo direito não pode ser transferido por ocasião do pacto constitutivo do Estado. Hobbes escreve: "Ninguém está obrigado, por qualquer contrato que seja, a não resistir a quem vier matá-lo, ou ferir ou de qualquer outro modo lesar seu corpo" ${ }^{25}$ Hobbes condensa a argumentação numa seqüência escalonada de afirmações: a) em todo homem existe o mais alto grau do medo; ${ }^{26} \mathrm{~b}$ ) através dele o homem concebe o mal que venha a sofrer como o maior de todos os males; ${ }^{27}$ c) por uma necessidade natural, o homem dele se esquiva pela luta ou pela fuga; ${ }^{28}$ d) ninguém está obrigado ao que é impossivel ${ }^{20}$ e) a morte é o maior mal que afeta a natureza. ${ }^{30}$ Hobbes encerra a seqüência, estendendo a não-obrigatoriedade da omissão à integridade física, caso aquele que está sendo ameaçado não seja forte o bastante para suportar a morte e, extensivamente, para resistir a danos físicos de qualquer espécie. ${ }^{31}$

À primeira vista, trata-se de um compacto silogístico cujos itens de a) até e) exercem a função de premissas, cabendo à última frase a conclusão do raciocínio. Avaliado, porém, com base na asserção da letra e) torna-se visível que o aparente fluxo silogístico se subdivide em uma série formal e outra material de proposiçōes. Enquanto a primeira se reporta ao agente, a segunda toma a morte por referência. $\mathrm{O}$ bloco de a) até $c$ ) aborda o efeito que o mais alto grau do medo provoca sobre a conduta de quem teme. $O$ ponto de partida da argumentação não é certo mal, mas, sim, um determinado estado psíquico, a saber: o maior dos medos. De onde se origina o medo em grau máximo, isso não se esclarece, de modo que as conse-

${ }^{24}$ Elements II, 1, 7, p. 111. "(S)upposing the not-resistance possible" ( versão portuguesa, p. 147).

${ }_{25}$ De cive II, 18. "Mortem, vel vulnera, vel aliud damnum corporis inferenti, nemo pactis suis quibuscunque obligatur non resistere"; versão inglesa, p. 39 (versão portuguesa, p. 56).

26 Ibidem. "Est enim in unoquoque gradus quidam timiditatis summum". A versão portuguesa segue a edição inglesa que no lugar do "mais alto grau do medo" contém "a certain high degree of fear". Ibidem. "(I)deoque necessitate naturali quantum potest fugit, intelligiturque aliter facere non posse. Ad talem gradum metus cum peruentum fuerit, non est expectandum, quin vel fuga, vel pugna sibi consulat". Ibidem. "Cum igitur nemo tenetur ad impossibile".

Ibidem. (I)lli quibus mors (quod maximum naturae malum est)".

${ }^{31}$ Ibidem. "(V)el quibus vulnera, aut alia corporis damna inferuntur, nec ad ea ferenda constantes satis sunt, ea ferre non obligantur". 
qüências do medo, e não a sua origem, dão significado ao feixe das três primeiras assertivas. Se a elas é juntado o enunciado ultra posse nemo obligatur, contido no item $d$ ), tem-se o princípio de que é impossível, por ocasião do mais intenso medo, omitir ações autodefensivas, uma vez que o mal que ameaça o agente lhe parece o maior dos riscos. Por conseguinte, ao não ser possível que haja uma obrigação que vincule a ação àquilo que é declarado impossível, fica excluída a alternativa de não poder tomar medidas preventivas em situações em que o medo atinge o clímax passional.

A conclusão tem validade universal. O raciocínio conclusivo supõe que haja uma situação psíquica que não admite, por definição, um comportamento alternativo àquele que o homem tem quando busca evadir-se dessa situação. Do princípio segundo o qual o impossível desobriga do contraditório segue-se que a renúncia a condutas autopreservativas é inexeqüível.

A armação lógica configura uma argumentação exclusivamente formal. Por mais concludente que o resultado fosse, incerto permaneceria o instante no qual o grau máximo do temor fosse atingido e, a partir do qual, estaria descartada a hipótese de que alguém ainda pudesse resistir ao medo. $O$ déficit da concretização não é, porém, apropriado para ser suprido por uma cadeia de argumentos que procuram provar, com vistas aos casos concretos do perigo de vida, a incapacidade inata ao homem de renunciar ao agir que lhe salvaguarde a conservação do ser físico. Tal prova, o teórico político inglês somente a teria oferecido se a conclusão parcial do acervo argumentativo houvesse incidido sobre o risco iminente da perda de vida. Hobbes tem de mostrar em que ocasiões o homem está incondicionalmente sujeito ao grau máximo do medo, ou seja, trata-se de provar que o homem está invariavelmente submetido ao mais alto grau do medo logo que a morte violenta o afeta em sua natureza, em razão da ameaça que o aflige em seu ser. Tal incidência parece evidente na assertiva da letra $e$ ), pela qual a morte é indicada como o maior dos males naturais, um argumento que Hobbes introduz de repente na corrente seqüencial do raciocínio. Contudo, com tal afirmação apenas se assevera que a morte é o sumo mal que afeta a natureza. Por essa frase não está dito em que consiste tal evento, e tampouco se diz por que o mais alto grau do medo é desencadeado pela morte como o mal natural por excelência. A concretização omitida é formulada por Hobbes alhures, quando constata: "Assim todo homem deseja o que é bom para ele, e foge do que é mau, principalmente daquilo que é o maior dentre os males naturais, a morte; e isso é feito por um certo impulso da natureza, tão certeiro quanto uma pedra que cai". ${ }^{32}$

Levando em consideração essa assertiva, a requerida concretização parece estar à mão. Uma vez que o homem por imposição natural - tal o argumento - não pode deixar de resistir à morte violenta que o ameaça, ele está desobrigado da

32 Ibidem I, 7. "Fertur enim unusquisque ad appetitionem eius quod sibi Bonum, \& ad Fugam eius quod sibi malum est, maxime autem maximi malorum naturalium, quae est mors; idque necessitate quadam naturae, non minore quam qua fertur lapis deorsum"; versão inglesa, p. 26 (versão portuguesa, p. 35). 
renúncia à luz do ultra posse nemo obligatur jurídico, pois a morte que o ameaça parece ser o acontecimento que o coloca num estado de medo em grau máximo. A consistência da suposta conclusão só pode ser aceita, se, e somente se, a morte efetivamente for evitada pelo homem graças a um imperativo natural indeclinável. Se tal não for o caso, também não se poderá concluir pela impossibilidade da nãoresistência ante a morte ameaçadora tomando por referência uma formulação jurídica positivada. A argumentação de Hobbes não deixa claro se os seres humanos esquivam-se necessariamente da morte violenta e, caso o façam, agem corretamente segundo a doutrina do estado natural hobbesiano. Somente se essa colocação puder ser referendada estarão preenchidas as condições sob as quais é possivel anuir à inferência da estrita impossibilidade de não resistir ao aniquilamento físico, sancionada pelo clássico enunciado do direito romano, segundo o qual nenhum homem está obrigado a fazer o impossível, mesmo se sua morte é ordenada pelo titular da soberania absoluta e ilimitada.

\section{Ações e paixões}

A questão se encontra embutida na teoria hobbesiana do surgimento das ações humanas. Somente no âmbito dessa doutrina pode-se esperar uma resposta para a pergunta que visa a esclarecer se o vínculo entre a ameaça à morte violenta e a subseqüente fuga ou resistência por parte do homem, sustentada como fato pelo teórico político inglês, refere-se ou não a uma constante comportamental inscrita na ordem natural das coisas, que, para Hobbes, rege o motus vitalis dos seres humanos.

Hobbes distingue no homem duas espécies de movimentos, chamados de voluntário e vital. A distinção entre um e outro não ancora sobre uma diversidade de princípios, mas tem a ver com a maneira como cada um deles surge no organismo. O movimento vital "inicia-se", segundo Hobbes, "com a geração, e continua sem interrupção durante toda a vida", e "não necessita da ajuda da imaginação" ${ }^{33}$ Tendo lugar entre a concepção e a morte do ser humano, essa espécie de movimento ocorre no interior do corpo e permanece infensa à vontade. Exemplos desse tipo de movimento são a circulação do sangue, o pulso, a respiração, a digestão, a nutrição e a excreção. O movimento voluntário, denominado por Hobbes movimento animal, se expressa na conduta externa do homem como "andar, falar e mover qualquer dos membros, da maneira como anteriormente foi imaginada pela mente" ${ }^{34}$ Contrariamente aos primeiros, "os movimentos voluntários dependem sempre de um pensamento anterior de como, onde e o que", pelo que "é evidente", diz Hobbes, "que a imaginação é a primeira origem interna de todos os movimentos voluntários". ${ }^{35}$

\footnotetext{
33

Leviathan I, 6, p. 37-38. “[...] begun in generation, and continued without unterruption through their whole life [...]; to which Motions there needs no help of Imagination" (versão portuguesa, p. 36).

34 Ibidem. "The other is Animall motion, otherweise called Voluntary motion; as to go, to speak, to move any of our limbes, in such manner as is first fancied in our minds".

35

Ibidem. "And because going, speaking, and the like Voluntary motions, depend alwayes upon a precedent thought of whither, which way, and what; it is evident, that the Imagination is the first internall beginning of all Voluntary Motion".
} 
Embora distintamente definidos, os movimentos voluntários procedem de movimentos internos. "Todas as ilusões são movimentos dentro de nós", escreve Hobbes, "vestígios daqueles que foram feitos na sensação", ${ }^{36}$ e a "imaginação é uma concepção que permanece, e pouco a pouco se degrada a partir e após o ato de sensação". " A causa da última é um objeto exterior cuja pressão, com a ajuda do sistema nervoso, é prolongada até o cérebro e o coração, causando uma contrapressão "cujo esforço", observa Hobbes, "por ser para fora, parece ser de algum modo exterior. E é a essa aparência, ou ilusão, que os homens chamam de sensação" . ."

$\mathrm{O}$ circuito dinâmico entre interior e exterior adquire no coração - e não no cérebro ou no órgão de cada sentido - sua referência vital. "As concepções ou aparições", escreve Hobbes, "nada têm de real, não são nada mais do que movimento em qualquer substância interna da cabeça. Esse movimento, que não é sustado no cérebro, mas propaga-se pelo coração, deve facilitar ou entravar necessariamente 0 movimento que se chama vital" ${ }^{39}$ Por um lado, o ser humano não sente 0 que se passa no interior do organismo e, por outro, percebe o incentivo ao movimento vital como deleite e o impedimento como dor, "o que nada mais é", afiança Hobbes, "do que um movimento relativo ao coração, ao passo que, como concepção, nada mais é do que movimento dentro do cérebro". ${ }^{40}$ As alternações do movimento vital constituem o esforço (conatus/endeavour) em constante movimento, ora em direção ao objeto, causando prazer e deleite, ora em sentido contrário do objeto, causando desprazer e dor. Hobbes sustenta a existência de tais movimentos, não obstante "os homens sem instrução não concebam que haja movimento quando a coisa movida é invisível, ou quando o espaço onde ela é movida (devido a sua pequenez) é insensível". ${ }^{41}$ Seja como for, tal esforço-em-movimento é também o primeiro início interno dos movimentos voluntários. Hobbes escreve: "Esses pequenos inícios do movimento, no interior do corpo do homem, antes de se manifestarem no andar, na fala, na luta e em outras ações visíveis, chamam-se geralmente esforço". ${ }^{42}$

${ }^{36}$ Ibidem I, 3, p. 20. "All Fancies are Motions within us, reliques of those made in the Sense" (versão portuguesa, p. 20).

37

Elements I, 3, 1, p. 8. "(I)magination being (to define it) conception remaining, and by little and little decaying from and after the act of sense" (versão portuguesa, p. 24).

38

Leviathan I, 1, p. 13-14. "The cause of Sense, is the Externall Body, or Object, which presseth the organ proper to each Sense [...] which pressure, by the mediation of Nerves, and other strings, and membranes of the body, continued inwards to the Brain, and Heart, causeth there a resistance, or counter-pressure, or endeavour at the heart, to deliver itself: which endeavour because Outward, seemeth to be some matter without. And this seeming, or fancy, is that which men call Sense" (versão portuguesa, p. 13).

Elements I, 7, 1, p. 28. "(C)onceptions or apparitions are nothing really, but motion in some internal substance of the head; which motion not stopping there, but proceeding to the heart, of necessity must there either help or hinder that motion which is called vital" (versão portuguesa, p. 49). Ibidem. "[...] which is nothing really but motion about the heart, as conception is nothing but motion within the head".

41 Leviathan I, 6, p. 38. "And although unstudied men, doe not conceive any motion at all to be there, where the thing moved is invisible; or the space it is moved in, is (for the shortnesse of it) insensible" ( versão portuguesa, p. 36).

42 Ibidem. "These small beginnings of Motion, within the body of Man, before they appear in walking, speaking, striking, and other visible actions, are commonly called Endeavour". 
Amparada pela declaração desse fato, a relação estabelecida por Hobbes entre imaginação e todos os movimentos voluntários afigura-se insustentável, de modo que "no lugar da identidade entre o movimento da imaginação e o princípio das ações voluntárias", escreve M.-I. Limongi, "seria preciso introduzir entre eles o movimento vital e uma referência à estrutura interna do nosso corpo". ${ }^{43}$

A alternativa parece incontornável. Ela assume a explicação mecânicomaterialista de Hobbes como uma questão de princípio e declina remeter, com Macpherson, o problema a postulados histórico-sociais. Com isso, retoma ao primeiro plano a suposta ambigüidade hobbesiana do uso de termos que incidem sobre uma explicação mecanicista e afetam, simultaneamente, uma teoria voluntarista do comportamento humano. À luz desse pressuposto, Hobbes teria embaralhado, por meio de associações imaginativas, o plano fenomênico das ações voluntárias e o plano mecânico-causal das explicações materialistas do movimento vital. Entretanto, o teórico político inglês não partilha do dualismo metafísico que ampara a hipótese. A idéia segundo a qual as máquinas não têm pensamentos e vontade é confrontada com a idéia de que o espírito pode ser concebido como matéria em movimento. Para Hobbes, prazer, deliberação e matéria organizada não se encontram em planos separados; pelo contrário, a vontade não lhe é mais significante do que matéria em movimento. Como o universo materialista hobbesiano desconhece uma fenda metafísica, o teórico político inglês também não necessita do emprego de conceitos equívocos para encobri-la e pode, assim, passar ao largo dos escolhos dualistas que envolvem a glândula pineal cartesiana. ${ }^{44}$

Somente à primeira vista a teoria hobbesiana da ação está desconectada do corpo do agente, o que justificaria a introdução de uma hipótese integradora para o que acontece entre imaginação e atos voluntários. Ao declarar que "as palavras 'bom', 'mau', e 'desprezível' são sempre usadas em relação à pessoa que as usa", Hobbes parece aventar a existência de um campo psicológico auto-oscilatório, cujo relativismo determinista tornar-se-ia inteligível apenas com base numa inequívoca matriz fisiológica. A plausibilidade da hipótese parece confirmada pela indeterminação atribuída pelo teórico político inglês ao objeto daquilo que os homens caracterizam por bom, mau ou indigno. "Mas seja qual for o objeto do apetite ou desejo de qualquer homem", escreve Hobbes, "esse objeto é aquele a que cada um chama de bom; ao objeto de seu ódio e aversão chama de mau, e ao de seu desprezo chama de vil e indigno" ${ }^{45} \mathrm{Na}$ verdade, a hipótese da estrutura interna do corpo, conectando aparentemente o movimento da imaginação com o movimento das ações voluntárias, coincide com a concepção hobbesiana do movi-

43 LIMONGI, Maria I. Hobbes e o conatus: da física à teoria das paixões. Discurso. (São Paulo), vol. 31,2000, p. 426.

44 Ibidem, p. 426-433. Cf. também WATKINS, J.W-N. Hobbes's system of ideas. A study in the political significance of philosophical theories. $2^{\text {nd }}$ revised edition. London: Hutchinson, 1973, (Reprint: Aldershot: Gower, 1989), p. 125-132.

45 Leviathan I, 6, p. 39: "But whatsoever is the object of any mans Appetite or Desire; that is it, which he for his part calleth Good: And the object of his Hate, and Aversion, Evill; And of his Contempt, Vile and Inconsiderable" (versão portuguesa, p. 37). 
mento vital. Como a constituição do corpo de um homem se encontra em constante modificação, "é impossivel", escreve Hobbes, "que as mesmas coisas nele provoquem sempre os mesmos apetites e aversões, e muito menos é possivel que todos os homens coincidam no desejo de um só e mesmo objeto". ${ }^{46}$ Longe de demarcar um desnivel categorial entre bom e mau, bem como entre apetite e aversão, Hobbes compromete a mutação e a conseqüente relatividade dos conceitos com a momentânea e respectiva constituição corpórea dos indivíduos.

Descartada a hipótese interpretativa do elo finalista entre imaginação e atos voluntários, readquire relevância a fundamentação hobbesiana do ultra posse nemo obligatur no âmbito da verdadeira liberdade dos súditos. A impossibilidade de o indivíduo ficar impassivel ante a morte violenta não remonta, na formulação precisa de Limongi, à distinção "entre a tendência a perseverar no ser [...] e a procura pela fuga deste ou daquele objeto, tal como este se apresenta à imaginação". ${ }^{47}$

Para o teórico político inglês, é irracional permanecer no estado de natureza. Propor-se sair desse estado e, simultaneamente, querer renunciar às razões que movem o propósito é impraticável, vale dizer, o ato de desistir da autopreservação constitui o contraditório do contrato que funda o estado civil. "Já no capítulo 14 [do Leviatã, José N. Heck]", escreve Hobbes, "mostrei que os pactos no sentido de cada um abster-se de defender seu próprio corpo são nulos". ${ }^{48}$ Tal argumento não mais se reporta à impossibilidade factual de determinado comportamento, mas tem por objeto a desobrigação de uma suposta declaração contratual que promete o impossível. Enquanto natural, a liberdade não é passivel de ser submetida a restrições voluntárias, razão por que é ocioso indicar o bem ao qual o homem é incapaz de renunciar voluntariamente. "Portanto", argumenta Hobbes, "se através de palavras ou outros sinais um homem parece despojar-se do fim para que esses sinais foram criados, não deve entender-se que é isso que ele quer dizer, ou que é essa a sua vontade, mas que ele ignorava a maneira como essas palavras e ações irão ser interpretadas". ${ }^{49}$ Hobbes adota no Leviatã a posição segundo a qual a verificação empírica, destinada a elucidar a origem do movimento vital, desvirtua in the long run o que se passa entre a imaginação e os atos voluntários. Para o teórico político inglês, tal desvirtuamento corre paralelo com a postulação gratuita de um telos na origem de todo movimento, ou com a admissão de uma inclinação anterior aos inícios do movimento vital no seio do organismo humano.

\footnotetext{
46 Ibidem. "And because the constitution of a mans Body, is in continuall mutation; it is impossible that all the same things should alwayes cause in him the same Appetites, and Aversions: much lesse can all men consent, in the Desire of almost any one and the same Object".

47 LIMONGI. Op. cit., p. 427.

48 Leviathan II, 21, p. 151. "I have shewn before in the 14. Chapter, that Covenants, not to defend a mans own body, are voyd" (versão portuguesa, p. 137).

49

Ibidem I, 14, p. 93-94. "And therefore if a man by words, or other signes, seem to despoyle himselfe of the End, for which those signes were intended; he is not to be understood as if he meant it, or that it was his will; but that he was ignorant of how such words and actions were to be interpreted" (versão portuguesa, p. 84).
} 
A doutrina hobbesiana da verdadeira liberdade dos súditos toma o estado natural como início da scientia civilis. Cotejada com a interpretação macphersoniana, a reconstrução hobbesiana não é nem histórica nem circunstancial, mas sim fictícia, muito aquém de qualquer tipo societário agregado ou dividido pelo meu/teu do capitalismo embrionário. O caráter ficcional do status naturalis hobbesiano reverte em benefício do indivíduo o clássico primado da pólis, isto é, não se trata mais de considerar os humanos como membros da cidade, mas de ver o que os leva a renunciar à precedência natural exercida sobre a coletividade. Ponto crítico da ficção doutrinária hobbesiana em relação à tradição aristotélica é a situação em que a obediência civil implica, para os súditos, a desistência do direito de resistir ao soberano que o ameaça com a morte violenta. Com base na ficção racional do contrato, Hobbes acaba descartando a prova empírica em apoio à impossibilidade natural de não oferecer resistência ao titular do poder político. Sem levar mais em consideração as limitações factuais do agir humano, resultantes da constituição física de cada indivíduo, os limites da obediência civil coincidem, na obra-prima do teórico político inglês, com os limites de um contrato cuja racionalidade obedece à imaginação que move imperceptivelmente os atos voluntários do indivíduo. À luz dessa teoria do surgimento das ações humanas, a verdadeira liberdade do súdito faz com que a promessa de não resistir à força fique sem efeito. "Um pacto", assegura Hobbes lapidarmente, "em que eu me comprometa a não me defender da força pela força é sempre nulo" ${ }^{50}$

Avaliada com as premissas de sua obra-prima, resta à teoria do movimento vital assumir tanto a conduta daqueles que evitam a morte violenta como naturalmente correta, quanto o comportamento de quem a provoca como naturalmente incorreto. As ações dos primeiros, ao confirmarem o incremento vital, são sadias, e o agir dos últimos, por contrariá-lo, é doentio. No Diálogo póstumo, depois de o parceiro jurista haver aprovado a punibilidade do suicida, o interlocutor filósofo duvida se um homem pode premeditadamente atentar contra a própria vida, e assevera: "Pois, natural e necessariamente, a intenção de um homem visa alguma coisa que é boa para si mesmo $€$ tende a preservá-la. E, portanto, creio eu, se ele se mata, deve-se supor que não está compos mentis (mentalmente sadio), mas fora de si por algum tormento interior ou pelo terror de algo pior que a morte". ${ }^{51}$ De acordo com essa afirmação, o suicida teria por natureza que agir necessariamente de outra maneira, vale dizer, o suicídio não invalida a teoria do movimento vital, mas é declarado pelo filósofo como um fato que desvia o curso natural dos mecanismos fisiológicos. Ao reportar-se a uma epidemia de loucura numa cidade grega que acometeu "apenas jovens donzelas, levando muitas delas a enforcarse", Hobbes relata que "esse desprezo pela vida" era visto por alguns como pro-

\footnotetext{
50 Ibidem I, 14, p. 98. "A Covenant not to defend my selfe from force, by force, is alwayes voyd" (versão portuguesa, p. 88).

51 Dialogue, EW VI, p. 88. "For naturally and necessarily the intention of every man aimth at somewhat which is good to himself, and tendeth to his preservation. And therefore, methinks, if he kill himself, it is to be presumed that he is not compos mentis, but by inward torment or apprehension of somewhat worse than death, destracted" (versão portuguesa, p. 107).
} 
vindo "de alguma paixão da mente", o que levou "os magistrados a despirem as que se enforcavam e a expô-las nuas publicamente". "A estória diz", arremata o teórico político inglês, "que isto curou essa loucura". ${ }^{2}$

Por mais convincente que seja a solução dada no Leviatã à relação da verdadeira liberdade dos súditos com a teoria das paixões, Hobbes não comprova a repetida afirmação, ao longo de sua obra, de que o ser humano foge da morte graças a uma ordem estritamente corporal. Ao caracterizar como doentio o comportamento fáctico que se opõe à concepção mecanicista do incremento vital, Hobbes ajusta conceitos antagônicos em seu estado ficcional de natureza. Na medida em que os fatos alegados não apenas contrariam a suposta matriz fisiológica, mas são tomados por afirmativas que se contradizem, o conteúdo explicativo das exceções indicadas por Hobbes tem a virtude de bloquear qualquer falsificação empírica de sua argumentação. A admissão de tal positivismo lógico afigurase conseqüente ante afirmações que equiparam o movimento vital com a circulação sangüínea, ${ }^{53}$ isto é, ao aumento desta última corresponde invariavelmente um acréscimo do primeiro. O homem, escreve J. Watkins, "deseja o que ajuda a circulação de seu sangue e odeia o que a impede. [...] o sexo é intrinsecamente prazeroso em virtude da aceleração do movimento vital que envolve" ${ }^{54} \mathrm{~A}$ generalização de meras congruências fisiológicas indica que os homens não se esquivam da morte, mas, pelo contrário, anseiam por ela como o maior dos bens, desde que 0 temor perante a morte violenta lhes traga, via aceleramento sangüíneo, um maximum em prazer. Ao chegar ao topo da integração com o movimento vital, a verdadeira liberdade dos súditos despenca de sua naturalidade e se converte fatalmente em seu oposto.

Envolver a teoria hobbesiana do surgimento das ações com antagonismos injeta na doutrina do estado de natureza o germe da dialética. Na fronteira entre o que é necessário e o que ocorre por acaso impera a lei da fatalidade. Reduzida a um conjunto de corpos em movimento, a realidade consiste num estado caótico que leva fatalmente à transmissão do movimento. Reduzida ao movimento, a liberdade é um caos que indicia a deliberação na origem dos atos fisicamente desimpedidos. Na ausência de elementos ou determinações essenciais, que possam explicar o movimento ou a liberdade, cada situação presente ou ocorrência fortuita identifica o verdadeiro estado natural dos homens. Eliminadas todas as variáveis históricas, a invariante natural equivale àquilo que não pode deixar de ser, de

52 Leviathan I, VIII, p. 56. "Likewise there raigned a fit of madnesse in another Graecian City, which seized onely the young Maidens; and caused many of them to hang themselves. This was by most then thought an act of the Divel. But one that suspected, that contempt of life in them, might proceed from some Passion of the mind, and supposing they did not contemne also their honour, gave counsell to the Magistrates, to strip such as so hang'd themselves, and let them hang out naked. This the story says cured that madnesse" (versão portuguesa, p. 52).

Cf. De corpore XXV, 12.

WATKINS. Hobbes's system of ideas. A study in the political significance of philosophical theories. $2^{\text {nd }}$ revised edition. London: Hutchinson, 1973, (Reprint: Aldershot: Gower, 1989), p. 110. “(H)e desires what helps the circulation of his blood, and hates what hinders it [...] Sex is intrinsically pleasurable because of the quickening of the vital motions it involves". 
modo que "basta um relance de olhos para", segundo Hegel, "encontrar aquilo que é necessário" ${ }^{55}$

À revelia do conceito hegeliano-especulativo de liberdade, a verdadeira liberdade dos súditos hobbesianos tem consistência metafísica. Ela concorre com a lei do cosmo como o vazio do nada com o ser parmenídico. "Os príncipes sucedemse uns aos outros, um juiz passa e outro vem; e mais, o céu e a terra passarão; mas nem um artigo da lei de natureza passará, porque ela é a eterna lei de Deus" ${ }^{56} \mathrm{O}$ axioma, pelo qual o mundo se sustenta por si mesmo, é que tudo é corpo e que nada é o que não é corpo. O nada físico não constitui o outro do ser, mas o vazio que permite o movimento, razão por que não há como contradizer-se a propósito de um mesmo ser. Atualmente existente ou não, a contradição é uma figura do discurso. Por ser como outro, o não-ser é dizível como falso e, como tal, contraditório ao que é dito como verdadeiro: "Imperioso é conceder aos velhos dialéticos", escreve Hegel, "as contradições por eles indiciadas no movimento; disso não resulta, porém, que o movimento não é, mas antes que o movimento é ele próprio a contradição presentificada" ${ }^{57}$ Contudo, tal contradição nada diz do movimento, que precisa ser pensado antes de ser dito. Para que o movimento seja pensável é preciso que o não-ser seja admitido como vazio. De acordo com a via física pós-parmenídica, "tendo em vista que "o não-ser é pensável como vazio, assim como o ser é pensável como pleno, [é] que o movimento é pensável". ${ }^{8}$

Imune a toda forma de dialética, a liberdade jusnaturalista de acepção hobbesiana é concebida à moda atomística primitiva. Por um lado, há uma indivisibilidade física (partículas corporais) e, por outro, uma divisibilidade ao infinito do lugar ocupado pelos átomos (espaço geométrico). A crítica de Hegel ao paradoxo jusnaturalista hobbesiano postula uma positividade dialética ao contraditório da liberdade, à luz da qual o tratamento eleático dado à contradição afigura-se meramente negativo. Mesmo que se admita um paralelo entre Zenão e Hobbes, o teórico político inglês permanece eleático. Para Hobbes, o que impede o movimento deixa claro o contraditório da definição de liberdade, à semelhança de Zenon que, ao levar em conta 0 movimento, confirma a posição eleática pela manutenção do ser parmenídico.

55 HEGEL, Georg W.-F. Über die wissenschaftlichen Behandlungsarten des Naturrechts, seine Stelle in der praktischen Philosophie, und sein Verhältnis zu den positiven Rechtswissenschaften. Jenaer Kritische Schriften (II). Hrsg. von H. Brockard und H. Buchner. Hamburg: Meiner, 1983, p. 100. "(W)enn man sich alles hinwegdenkende, was eine trübe Ahndung unter das Besondere und Vergängliche rechnen kann, [...], so bleibt der Mensch unter dem Bilde des nackten Naturzustandes oder das Abstraktum desselben mit seinen wesentlichen Möglichkeiten übrig, und man hat nur hinzusehen, um das zu finden, was notwendig ist".

56 Leviathan II, 26, p. 192. "Princes succeed one another; and one Judge passeth, another commeth; nay Heaven and Earth shall passe; but not one title of the Law of Nature shall passe; for it is the Eternall Law of God" (versão portuguesa, p. 172).

HEGEL. Wissenschaft der Logik II (1813-16). Hrsg. von G. Lasson. Hamburg: Meiner, 1969, p. 59. "Man muss den alten Dialektikem die Widerprüche zugeben, die sie in der Bewegung aufzeigen. Aber daraus folgt nicht, dass darum die Bewegung nicht ist, sondern vielmehr, dass die Bewegung der daseiende Widerspruch ist".

WOLFF, Francis. Dois destinos possiveis da ontologia: a via categorial e a via fisica. Analytica (Rio de Janeiro), v. 1, n. 3, 1996, p. 219. 


\section{Observações conclusivas}

A figura paradigmática do eleatismo atomista hobbesiano é o solipsista sozinho no mundo. ${ }^{59}$ Ele subsiste no desaparecimento do cosmo e perfaz o ser zeroquilômetro do conhecimento filosófico. Aniquilado o universo, à exceção de um único ser humano, Hobbes assevera:

Digo, portanto, que restaria a esse homem idéias do mundo e de todos os corpos que ele possuia antes de sua supressão, vistos por seus olhos ou percebidos por qualquer um de seus sentidos, isto é, a memória e imaginação de grandezas, movimentos, sons, cores e assim por diante, bem como de suas ordens e partes, tudo coisas que nada são senão idéias e fantasmas, ocorrendo internamente como acidentes a quem imagina, não obstante elas apareçam como externas e de todo independentes das virtudes da mente. E essas são as coisas às quais ele daria nomes, separando umas das outras e juntando umas às outras. ${ }^{60}$

Longe de dar a palma ao senso comum que indistingue o sensível do inteligível, a ficção do cosmo aniquilado opera com os extremos epistemológicos do empirismo e do racionalismo filosóficos. Por um lado, a percepção do indivíduo é tudo, quer dizer, não há mundo à revelia do que é percebido e, por outro, nada do que é inerente ao dado sensível fica inteligível por acaso, vale dizer, torna-se explicável sem o poder pessoal da razão de atribuir nomes ao pensado para os fins do raciocínio. ${ }^{61}$ A geometria consiste na demonstração dos efeitos causados pelas definições do agente que raciocina, e a física é a ciência que parte de hipóteses à luz das quais os efeitos da natureza, sensificados pelas percepções, podem ser investigados como se fossem gerados pelo conhecimento. "E2 "Enquanto o geômetra goza", segundo D. Jesseph, "da vantagem de lidar com demonstrações fundadas sobre o saber de verdadeiras causas, o cientista natural tem que raciocinar ex hypothesi e tentar explicar os fenômenos da natureza trazendo a prova mais provável do fenômeno em questão" ${ }^{63}$. Como os ínfimos corpúsculos do mecanicismo hobbesiano permanecem inobserváveis, o método hipotético da ciência natural elimina o absurdo por aquilo que é definido e reduz as causas mecânicas inteligíveis ao movimento dos corpos e ao conseqüente impacto corpóreo.

Cf. TUCK. Hobbes. Oxford: University Press, 1989, p. 56 (versão portuguesa, p. 60-67).

De corpore II, 7, 1. "Dico igitur, remansuras illi homini, mundi et corporum omnium, quae, ante sublationem eorum, oculis aspexerat, vel aliis sensibus perceperat, ideas, id est memoriam imaginationemque magnitudinum, motuum, sonorum, colorum, \&c. atque etiam eorum ordinis et partium; quae omnia etsi ideae tantum et phantasmata sint, ipsi imaginanti interne accidentia, nihilominus tanquam externa, et a virtute animi minime dependentia, apparitura esse. His itaque nomina imponeret, haec subtraheret et componeret" (versão inglesa, p. 43-44).

Ibidem. ".... philosophari, vel omnino ratiocinari, vel cui rei nomen aliquod ratiocinandi causa imponere posset".

Ibidem IV, 25, 1.

63

JESSEPH, Douglas. Hobbes and the method of natural science. In: SORELL (Ed.). The Cambridge companion to Hobbes. New York: Cambridge University Press, 1996, p. 88. "Where the geometer enjoys the advantage of dealing with demonstrations founded on knowledge of true causes, the natural scientist must reason ex hypothesi and try to explain the phenomena of nature by adducing the most probable cause of the phenomenon in question". 
A posse e o uso da linguagem pelos homens fazem com que a ciência seja possivel, razão pela qual a prática da ciência inicia com a linguagem científica de impor nomes para registrar nossos pensamentos e significar nossas concepções. Segundo Hobbes, os humanos não estão imersos numa linguagem-mundo, mediante a qual se entendem naturalmente, ao falarem infinitamente das coisas uns aos outros. $\mathrm{O}$ universo é o mundo no qual os indivíduos se movem não menos evidentemente do que é visto, tocado e pensado por eles. A razão, afiança Hobbes, "nada mais é do que cálculo (isto é, adição e subtração) das conseqüências de nomes gerais estabelecidos para marcar e significar nossos pensamentos. Digo marcar quando calculamos para nós próprios, e significar quando demonstramos ou aprovamos nossos cálculos para os outros homens" ${ }^{64}$ Produzidas fisicamente como percepção sensivel pelos corpos exteriores, as coisas singulares aparecem a nós como cristalizações mecânicas externas, imunes à atividade da razão e avessas à operosidade científica. "É somente a partir da perspectiva da linguagem", escreve Limongi, "quando se pensa a partir dos nomes e se pergunta pela sua significação, que as representações podem ser reduzidas a um mero estado subjetivo, que não remete a nada, a nenhuma coisa, além da imaginação mesma". ${ }^{65}$

O solipsista hobbesiano não considera o falso um não-ser. Para o teórico político inglês, verdadeiro e falso são atributos da linguagem, "de modo que na correta definição de nomes reside o primeiro uso da linguagem, o qual consiste na aquisição de ciência; e na incorreta definição, ou na ausência de definições, reside o primeiro abuso, do qual resultam todas as doutrinas falsas e destituídas de sentido" ${ }^{66}$ Com vistas à pertinência científica de sua ciência civil, o teórico político inglês realça como "o maior benefício da linguagem o fato de podermos dar comandos e entender comandos. Pois, na ausência deles não haveria nenhuma sociedade entre os homens, nenhuma paz e, por conseguinte, nenhuma disciplina, mas, primeiro, selvageria, depois solidão e, em vez de lares, cavernas". ${ }^{67}$

64 Leviathan I, 5, p. 32. "For Reason, in this sense, is nothing but Reckoning (that is, Adding and Substracting) of the Consequences of generall names agreed upon, for the marking and signifying of our thoughts; I say marking them, when we reckon by our selves; and sinifying, when we demonstrate, or approve our reckonings to other men" (versäo portuguesa, p. 31). LIMONGI. A semântica do materialismo de Hobbes. Analytica, Rio de Janeiro, v. 5, n. 1-2, p. 134, 2000.

Leviathan I, 4, p. 28. "So that in the right Definition of Names, lyes the first use of Speech; which is the Acquisition of Science: And in wrong, or no Definitions, lyes the first abuse; from which proceed all false and senslesse Ténets" (versão portuguesa, p. 27).

De homine 10,3 . "(Q)uod imperare et imperata intelligere possimus, beneficium sermonis est, et quidem maximum. Nam sine eo nulla esset inter homines societas, nulla pax, et consequenter nulla disciplina; sed feritas primo, et deinde solitudo, et pro domiciliis latibula" (versão inglesa, p. 39-40). 


\section{Referências bibliográficas}

ADAM, Armin. Despotie der Vernunft. Hobbes, Rousseau, Kant, Hegel. Freiburg/München: Verlag K. Alber, 1999.

BAPTISTA, Lígia P. O estatuto da paz na teoria politica hobbesiana. Cademos de história e filosofia da ciência. (Campinas), s. 3, v. 5, n. 1-2, Unicamp, 1995.

BARNOUW, JEFFREY. Le vocabulaire du conatus. ZARKA, Yves Ch. (Ed.). Hobbes et son vocabulaire. Etudes de lexicographie philosophique. Paris: J. Vrin, 1992.

BERTI, Enrico. Hegel und Parmenides oder: Warum es bei Parmenides noch keine Dialektik gibt. In: RIEDEL, Manfred (Hrsg.). Hegel und die antike Dialektik. Frankfurt a/Main: Suhrkamp, 1990.

BOBBIO, Norberto. Thomas Hobbes. Turim: Einaudi, 1989. Trad. do italiano por Carlos N. Coutinho. Rio de Janeiro: Campus, 1991.

. Hobbes e il giusnaturalismo. KING, Preston (Ed.). Thomas Hobbes. Critical Assessments, vol. III (Politics and law). London/New York: Routledge, 1993.

BOURGEOIS. Bemard. Le droit naturel de Hegel: commentaire. Contribution à l'étude de la genèse de la spéculation hégélienne à Iena. Paris: J. Vrin, 1986.

DIELS-KRANZ. Die Fragmente der Vorsokratiker. Hrsg. von W. Kranz. Berlin, Weidemann, 1951. Trad. do alemâo por M. Spinelli (parcialmente). Porto Alegre, Edipucrs, 1998 (Coleção Filosofia).

DIX, Bruno. Lebensgefährdung und Verpflichtung bei Hobbes. Würzburg: Königshausen \& Neuman, 1994 (Reihe Philosophie).

DUFOUR, Alfred. Droits de l'homme, droit naturel et histoire. Paris, PUF, 1991.

GOLDSMITH, Maurice. Hobbes's science of politics. New York: Columbia University Press, 1966.

- Hobbes on law. SORELL, Tom. (ed.). The Cambridge companion to Hobbes. New York: Cambridge: University Press, 1996.

GOUGH, John. The social contract. A critical study of its development. 2. ed. Oxford: Oxford University Press, 1977.

GRUNDSTEIN, Nathan D. The futures of prudence: pure strategy and Aristotelian and Hobbesian strategists. Hudson, Ohio: Enterprise Achievement Associates, 1983.

HAMPTON, Jean. Hobbes and the social contract tradition. Cambridge/New York: Cambridge University Press, 1988.

HECK, José N. Jusnaturalismo e dialética. Veritas. (Porto Alegre), v. 44, n. 4, 1999.

. \& LIMA-RASMUSSEN, Roberta. Direito natural e leis civis em Thomas Hobbes. Fragmentos de Cultura. (Goiânia), v. 10, n. 3, 2000.

HEGEL. Wissenschaft der Logik (1812), (1813-16). Hrsg. von G. Lasson. Hamburg: Meiner, 1969.

. Wissenschaft der Logik. Das Sein (1812). Hrsg. von F. Hogemann und W. Jaeschke. Hamburg: Meiner, 1986.

1990

Wissenschaft der Logik. Die Lehre vom Sein (1832). Hrsg. von H-J. Gawoll. Hamburg: Meiner

. Wissenschaftliche Behandlungsarten des Naturrechts. In: Jenaer kritische Schriften (II). Hrsg. von H. Brockard und H. Buchner. Hamburg: Meiner, 1993,

HOBBES, Thomas. De cive or the citizen. Ed. by Sterling Lamprecht. Westport, Conn.: Greenwood Press, 1982. Trad. do inglês por Renato J. Ribeiro. São Paulo: Martins Fontes, 1992. 
. Leviathan. Ed. by R. Tuck. Cambridge/New York: Cambridge University Press,1991. Trad. do inglês por João P. Monteiro e Maria B. da Silva. São Paulo: Abril Cultural, 1974 (Col. Os Pensadores).

The elements of law natural \& politic. Ed. by Ferdinand Tönnies. Second imp. Cornwall: Frank Cass, 1984. Trad. do inglês por Fernando Couto, Porto: RÉS-Editora, 1999. (Col. Resjurídica).

Metaphysical Writings. Ed. by Mary Wh. Calkins. La Salle: Illinois, 1989.

- Malmesburiensis opera philosophica quae latine scripsit omnia in unum corpus nunc primum collecta. Studio et labore Gulielmi Molesworth. V vol. Londini: Joannem Bohn, 1839-1845 (Reprint: Aalen-Scientia, 1966).

- Hobbes über Freiheit. Edição bilingüe (latim/alemão) dos três primeiros capitulos do De Cive. Editados por GEISMANN, Georg \& HERB, Karlfriedrich. Würzburg: Königshausen \& Neumann, 1988.

J. Vrin, 1973.

Critique du De mundo de Thomas White. JACQUOT, Jean \& JONES, Harold Wh. (Ed.). Paris:

- Dialogue between a philosopher and a student of the common laws of England. Chicago: University Press. Trad. do inglês por Maria C. G. Cupertino. São Paulo: Landy, 2001.

HOFFMAN, Piotr. Freedom, equality, power. The ontological consequences of the political philosophies of Hobbes, Locke, and Rousseau. New York: P. Lang, 1999.

HORKHEIMER, Max. Anfänge der bürgerlichen Geschichtsphilosophie. Frankfurt/Main: Suhrkamp, 1971.

JESSEPH, Douglas M. Squaring the circle. Tthe war between Hobbes and Wallis Chicago: University of Chicago Press, 1999.

KAVKA, Gregory S. Hobbesian moral and political theory. Princeton: Princeton University Press, 1986.

KERSTING, Wolfgang. Rechtsverbindlichkeit und Gerechtigkeit bei Thomas Hobbes. Bemerkungen anlässlich der zugleich naturrechtlichen und modernitätseuphorischen Hobbes-Interpretation von Norbert Campagna. Studia Leibnitiana, XXII, 1998.

— Vertrag, Souveränität, Representation. Zu den Kapiteln 17-22 des Leviathan. Thomas Hobbes - Leviathan oder Stoff, Form und Gewalt eines bürgerlichen und kirchlichen Staates (Hrsg.). Berlin: Akademie Verlag, 1996 (Klassiker Auslegen, Bd. 5).

—. Positives Rechts und Gerechtigkeit bei Thomas Hobbes. Politik und Recht. Abhandlungen zur politischen Philosophie der Gegenwart und zur neuzeitlichen Rechtsphilosophie. Göttingen: VelbrückWissenschaft, 2000.

Thomas Hobbes. Zur Einführung. 2. Überarb. Aufl. Hamburg: Julius, 2002.

LIMONGI, Maria I. Hobbes e o conatus: da física à teoria das paixões. Discurso. (São Paulo), v. 31, 2000.

Hobbes. Rio de Janeiro: Jorge Zahar Editor, 2002.

LUDWIG, Bernd. Die Wiederentdeckung des epikureischen Naturrechts: zu Thomas Hobbes' philosophischer Entwicklung von De Cive zum Leviathan im Pariser Exil, 1640-1651. Klostermann, 1998.

Hobbes-Kant-Höffe. Eine moderne Renaissance des Naturrechtsdenkens. In: KERSTING, Wolfgang (Hrsg.). Gerechtigkeit als Tausch? Auseinandersetzungen mit der politischen Philosophie Otfried Höffes. Frankfurt a/Main: Suhrkamp, 1997.

. Die Wiederentdeckung des epikurischen Naturrechts. Frankfurt: Klostermann, 1998. 
MACPHERSON, Crawford B. The political theory of possessive individualism - Hobbes to Locke. London/Oxford/New York: Oxford University Press, 1962. Trad. do inglês por Nelson Dantas. Rio de Janeiro: Paz e Terra, 1979.

MADANES, Leiser. Hobbes e o poder arbitrário. Discurso. (São Paulo), 28, 1997.

MALUSCHKE, Günther. A soberania popular: enigma não-resolvido da democracia. Philósophos. (Goiânia), v. 5, n. 1, 2000.

MARX, Karl. Das Kapital, Kritik der politischen Ökonomie. Bd. I. Berlin: Dietz Verlag, 1972, p. 184, nota 42 (MEW, Bd. 23). Trad. do alemäo por Reginaldo Sant'Anna. 13. ed. Rio de Janeiro: Bertrand Brasil, 1989.

PRAUSS, Gerold. Hegels Parmenides-Deutung. Kant-Studien 57, 1987.

RIBEIRO, Renato J. Hobbes, Jaime I e o direito inglês. Filosofia Politica. (Porto Alegre), n. 6, 1989.

—_. A marca do Leviatã. São Paulo: Ática, 1978.

Letras, 1990.

A glória. CARDOSO, Sérgio et. al. Os sentidos da paixão. São Paulo: Funarte/Companhia das

Apresentação de Do cidadão. São Paulo: Martins Fontes, 1992.

- Sobre a má fama em filosofia política: Hobbes. BONI, Luís. A. Finitude e transcendência. Festschrift em homenagem a Ernildo Stein. Petrópolis: Vozes, 1996.

Hobbes: o medo e a esperança. In: WEFFORT, Francisco C. (Org.). Os clássicos da política. São Paulo: Ática, 1993. UFMG,1999.

Ao leitor sem medo. Hobbes escrevendo contra o seu tempo. 2. ed. Belo Horizonte: Editora ROUSSEAU, Jean-J. Du contrat social; ou, principes du droit politique. In: Oeuvres complètes III. Paris: Gallimard, 1964. Trad. do francês por Lourdes S. Machado. São Paulo: Abril Cultural, 1973 (Col. Os Pensadores/XXIV).

- Discours sur l'origine et les fondements de l'inégalité parmi les hommes. In: Op. cit. Trad. do francês por Iracema G. Soares e Maria C. Reveri Nagle. Brasília/São Paulo. Editora UnB/Ática, 1989.

RUMPF, Helmut. Carl Schmitt und Thomas Hobbes. Ideelle Beziehungen und aktuelle Bedeutung. Berlin: Duncker \& Humblot, 1972.

SCHMITT, Carl. Der Staat als Mechanismus bei Hobbes und Descartes. Archiv für Rechts- und Sozialphilosophie. (Berlin). Bd. XXX, 1936/37.

. Der Leviathan in der Staatslehre des Thomas Hobbes. Sinn und Fehlschlag eines politischen Symbols (1938). 2. Aufl. Stuttgart, 1995.

- Politische Theologie. Vier Kapitel zur Lehre von der Souveränität (1922). 5. Aufl. Berlin: Duncker \& Humblot. 1990.

Der Begriff des Politischen (1932). 6. Aufl. Berlin: Duncker \& Humblot, 1979. Trad. do alemão por Á. Valls. Petrópolis: Vozes, 1992.

Die vollendete Reformation. Bemerkungen und Hinweise zu neuen LeviathanInterpretationen. Der Staat. Zeitschrift füre Staatslehre, öffentliches Recht und Verfassungsgeschichte. (Berlin), 4. Bd., 1965.

Humblot, 1988.

Verfassungslehre (1928). 2. Aufl. Berlin: Dunckler \& Humblot, 1989. 
SCHUHMANN, Karl. Geometrie und Philosophie bei Thomas Hobbes. Philosophisches Jahrbuch 92, 1985.

SKINNER, Quentin. The context of Hobbes's theory of political obligation. CRANSTON \& RICHARD (Ed.) Hobbes and Rousseau. A collection of critical essays. New York: Garden City, 1972.

- The foundations of modern political thought. Cambridge: University Press, 1978 (reprint, 1979, 1980). Trad. do inglês por Renato J. Ribeiro e Laura Teixeira Motta. São Paulo: Companhia das Letras, 1996.

- Reason and rhetoric in the philosophy of Hobbes. Cambridge: Univeristy Press, 1996. Trad. do inglês por Vera Ribeiro. São Paulo: Unesp/Cambridge, 1999.

STRAUSS, Leo. The political philosophy of Hobbes. Its basis and its genesis. Oxford: University Press, 1936.

Natural right and history. Chicago: University Press, 1953.

TUCK, Richard. Hobbes. Oxford: University Press, 1989.

WARRENDER, H. The political philosophy of Hobbes. His theory of obligation. Oxford: Clarendon Press, 1957.

WEISS, Ulrich. Das philosophische System von Thomas Hobbes. Stuttgart-Bad Cannstatt: FrommannHolzboog, 1980.

WERGER, Rainer. Naturzustand und Staat bei Thomas Hobbes. (Mimeo). Diss. Bonn, 1984.

WOLF, Francis. Aristote et la politique. Paris. Presses Universitaires de France, 1991. Trad. do francês por Thereza Ch, Stummer e Lygia A. Watanabe. Säo Paulo: Editorial, 1999.

- WOLF, Francis. Dois destinos possiveis da ontologia: a via categorial e a via física. Analytika. (Rio de Janeiro), v. 1, n. 3, 1996.

WOLFERS, Benedikt. "Geschwätzige Philosophie" - Thomas Hobbes' Kritik na Aristoteles. Würzburg: Königshausen \& Neumann, 1991.

WOLLMANN, Sérgio. O conceito de liberdade no Leviatã de Hobbes. Porto Alegre: Edipucrs, 1993.

ZARKA, Yves Ch. La décision métaphysique de Hobbes. Conditions de la politique Paris: J. Vrin, 1997.

- Hobbes et la pensée politique moderne. Paris: Presses universitaires de France, 1995.

. Identité et ipséité chez Hobbes et Locke. Philosophie, n. 37, 1993.

(Ed.) Hobbes et son vocabulaire. Etudes de lexicographie philosophique. Paris: J. Vrin, 1992.

- A invenção do sujeito de direito. Filosofia Política - Nova Série. (Porto Alegre), v. 1, 1997.

- First philosophy and the foundations of knowledge. SORELL, Tom. (Ed.). The Cambridge companion to Hobbes. New York: Cambridge: University Press, 1996. 